\title{
Non-Surgical Endodontic Retreatment of Anterior Tooth with a Large Periapical Lesion and Extruded Guta Percha with 36 Months Follow-Up: A Case Report
}

\author{
Hatice Sağlam \\ Faculty of Dentistry, Biruni University, Istanbul, Turkey \\ Email: hsaglam@biruni.edu.tr
}

How to cite this paper: Sağlam, H. (2021) Non-Surgical Endodontic Retreatment of Anterior Tooth with a Large Periapical Lesion and Extruded Guta Percha with 36 Months Follow-Up: A Case Report. Open Journal of Stomatology, 11, 166-178. https://doi.org/10.4236/ojst.2021.114014

Received: January 15, 2021

Accepted: April 23, 2021

Published: April 26, 2021

Copyright $\odot 2021$ by author(s) and Scientific Research Publishing Inc. This work is licensed under the Creative Commons Attribution International License (CC BY 4.0).

http://creativecommons.org/licenses/by/4.0/

\begin{abstract}
Root canal treatment failure depends on many factors. Overfillings, insufficient fillings, missing canals, failure to provide a complete apical plug, and impermeability of coronal restoration are some of them. Failed root canal treatment may not always manifest itself immediately after treatment. Sometimes, root canal treatments, which have not been done well, can manifest themselves with extensive lesions and severe pain in the apical after a long time. Apical resection may be considered as a solution in lesions that are too large to be treated, but retreatment without surgery should be attempted beforehand. Thus, the patient may have recovered from unnecessary surgical procedures and treated with a more conservative method. This case presents the non-surgical retreatment of a left lateral tooth with a large periapical lesion with extruded gutta percha followed by a 36-month follow-up.
\end{abstract}

\section{Keywords}

Overfilling, Retreatment, Root Canal Treatment

\section{Introduction}

A three-dimensional obturation of the root canal system after shaping and cleaning is important for successful endodontic therapy [1]. If there is a procedural mistake about the apical border, it will lead to treatment failure. Overfilling is also one of these mistakes and it may appear especially in immature cases, over instrumented teeth or resorbed apices. Treatment failures following extruded gutta-percha (GP) are due to factors such as persistent root canal infection, reinfec- 
tion resulting from apical transportation of bacteria during over instrumentation and foreign body reaction elicited by the extruded material itself [2]. Root canal treatment failure with overfilling material can be treated with non-surgical method, surgical method or both of them.

There are several methods of non-surgical treatment of periapical lesions such as conservative root canal therapy without adjunctive therapy, decompression technique, active nonsurgical decompression technique, aspiration and irrigation technique, lesion sterilization and repair therapy, aspiration through the root canal technique and apexum procedure. There are some points that should be considered when root canal treatment will be performed in teeth with large lesion. In these cases, retreatment should be tried first with the conventional method. Even if it does not completely heal the lesion, it is aimed to reduce the size of the lesion with the retreatment of the relevant tooth, thus protecting the adjacent tissues as much as possible in case of a possible surgical treatment. In addition, adjacent teeth may be damaged during the cleaning of the lesion area during surgical treatment, and in the future, they may lose their vitality and require root canal treatment. This situation can be prevented with non-surgical treatment.

Periradicular surgery is indicated in case of significant overextension of filling material resulting in periradicular pathosis with symptoms, true periradicular cysts with completely enclosed epithelium-lined cavities which are not expected to resolve after nonsurgical dental treatment, persistent periradicular pathosis and correction of deficiencies in previous treatment [3]. Endodontic surgery aims to remove the periapical pathosis and to give the teeth its whole function. Surgical treatment requires a second operation, patient cooperation and is less satisfactory in this respect. The root end procedures are associated with many drawbacks such as limited accessibility, risk of perforation and fractures or cracks at the root end and the need for high cost equipment such as ultrasonic systems and surgical microscopes [4]. The process of root end resection and cavity preparation often results in microcracks within dentin and weakens the remaining root structure [5]. Apical resection also causes a decrease in crown root ratio. For these reasons, nonsurgical retreatment should be tried before surgical treatment and the tooth should be given a chance to activate its own healing mechanism. This case report presents the non-surgical endodontic retreatment of anterior tooth with a large periapical lesion and extruded gutta percha and its 36-month follow-up period.

\section{Case Report}

A 17-year-old female patient was referred to our clinic with a chief complaint of intermittent pain in the upper front region. She gave a history of mild pain and occasional swelling. Radiographic examination revealed root canal treatment performed in the upper left lateral (number 22) (Figure 1). The gutta percha was extruded about four milimetres. There was also large periapical lesion at the apical region of 22 and the lesion extended to 21 and 23. However the vitality 


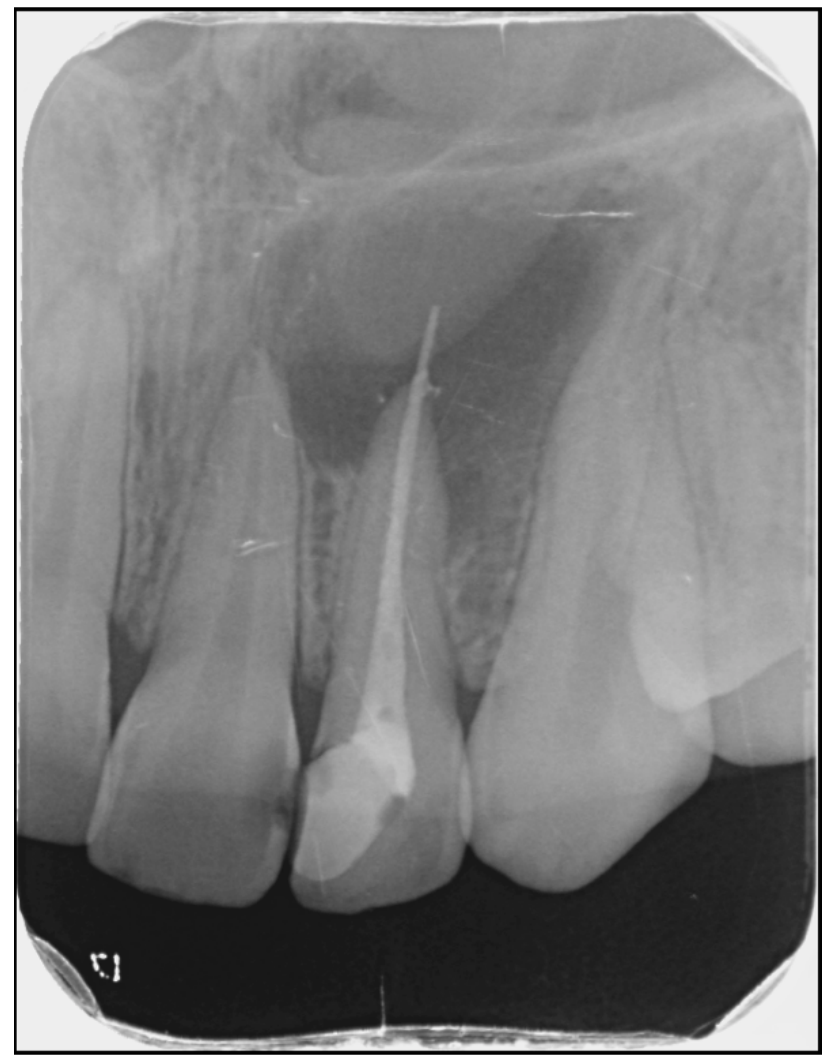

Figure 1. Preoperative radiography.

tests revealed that teeth 21 and 23 were vital. After the patient and her family were informed about the treatment process, approval was obtained for the treatment. Local anestesia was applied for the patient comfort. The access cavity was opened. Gutta-percha in the coronal part was removed with gates glidden burs. Then, the gutta-percha in the middle of the root was removed with $\mathrm{H}$ files. The old canal filling in the middle trio was removed by using $\mathrm{H}$ files in ISO 15 , 20 and 25 sizes up and down motion. Copius irrigation with sodyum hypoclorite (\%2.5) was performed between the files. $\mathrm{H}$ file was used again for the apical part. In order to remove the extruded material in the apical part in one piece, it was aimed to squeeze the gutta percha between root kanal wall and $\mathrm{H}$ file. When ISO $15,20,25 \mathrm{H}$ files were used again at the apical part, it was observed that the extruded material at the apical region did not get stuck in the foramen. In such a state that the file size $\# 25$ could pass by the gutta and go out of the foramen, but the file was still not large enough to squeeze the extruded material at the foramen against the canal wall. Then, the number $30 \mathrm{H}$ file was introduced. File size \#30 was stuck at the apical, but it was used carefully to avoid deformation that would cause the extruded material to break. When the radiograph is taken to see the apical part; we saw that the extruded part was deformed enough to be considered broken in its place without leaving the apical region (Figure 2). After a few trials with $\mathrm{H}$ file size $\# 30$, the extruded part came out with this file in one piece. A radiograph was taken to confirm the gutta percha removal (Figure 3). 


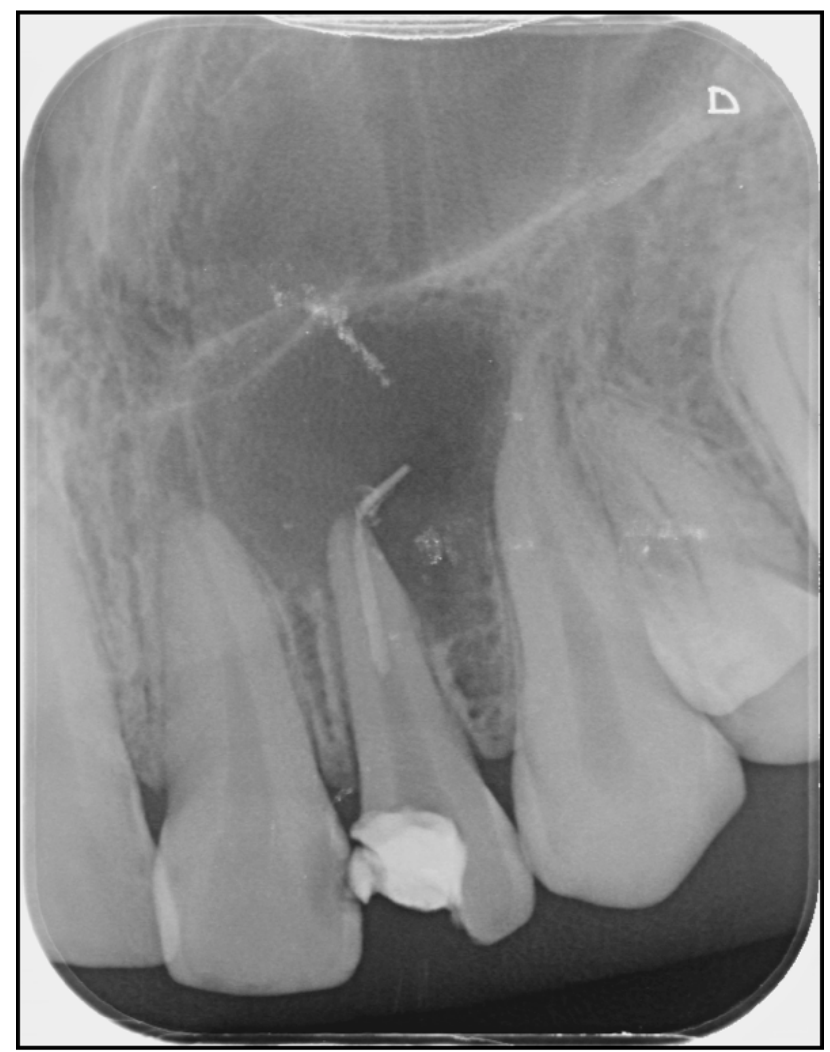

Figure 2. Nearly broken gutta percha.

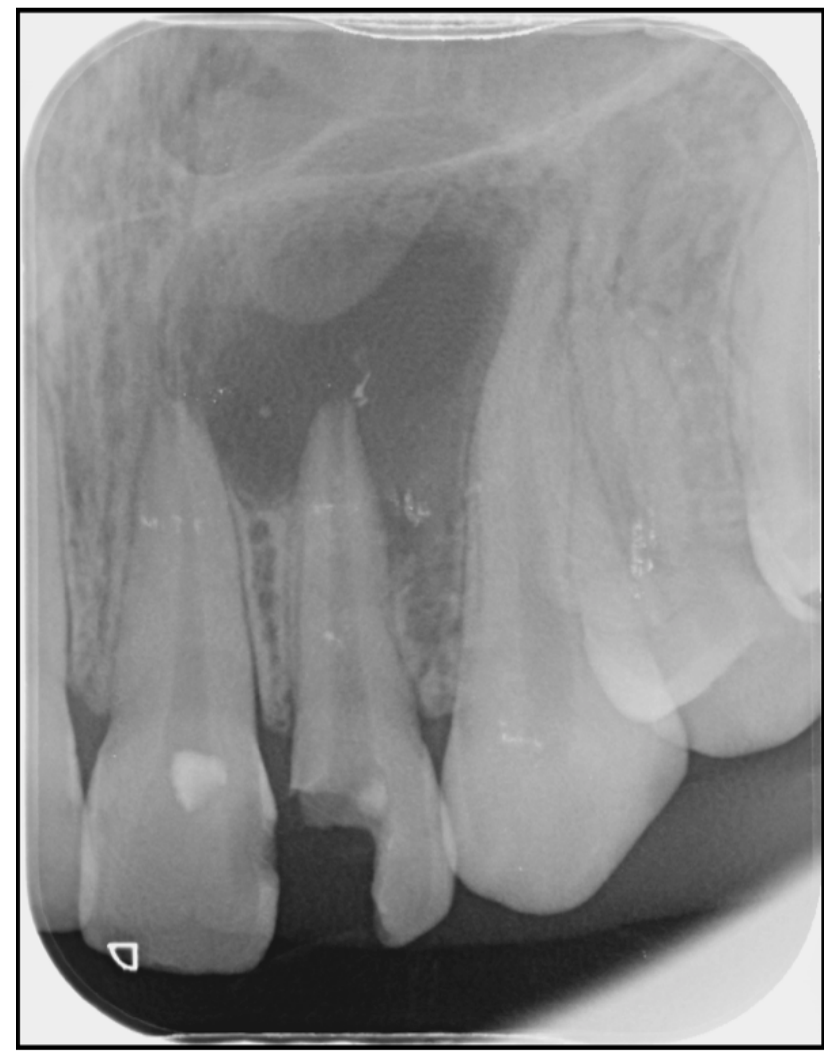

Figure 3. Confirming of Gutta percha removal. 
Later, the apical diameter was prepared with $\mathrm{K}$ and $\mathrm{H}$ files up to size \#50 in order to clean the necrotic root structure. Copius irrigation was performed between each file. After the master apical diameter was prepared to size \#50, root canal preparation was completed with the step-back technique. Serous exudate drained through the canal. After final irrigation the tooth closed with temporary filling. Drainage did not stop and dressing was continued for the next three sessions. The tooth was asymptomatic during the sessions. At the fifth appointment the tooth was ready for obturation. There are various techniques used in filling root canal systems. Cold lateral compaction, warm lateral compaction, continious wave compaction, thermoplasticized gutta-percha injection, carrier based gutta percha, Mcspadden thermomecanical compaction can be counted as the main ones. Another material that can be used in teeth with large apical diameters is MTA. Clinically MTA is a biocompatible material with good sealing ability. However because of long setting time and being an expensive material, patient didn't accept to treatment with MTA. Furthermore, a conical shape was given to the root canal with the step-back technique. There were no irregularities in the root canal wall after preparation. There is a risk of vertical root fracture and overfilling gutta percha or sealer that cannot be retrieved from the periradicular tissues with the warm techniques. Therefore, cold lateral compaction technique was used in this case. After the esential adhesive steps, the final restoration was made with composite resin (Z350, 3M ESPE, USA) (Figure 4). It was seen that the root canal filling was a little extruded in the postoperative film. However,

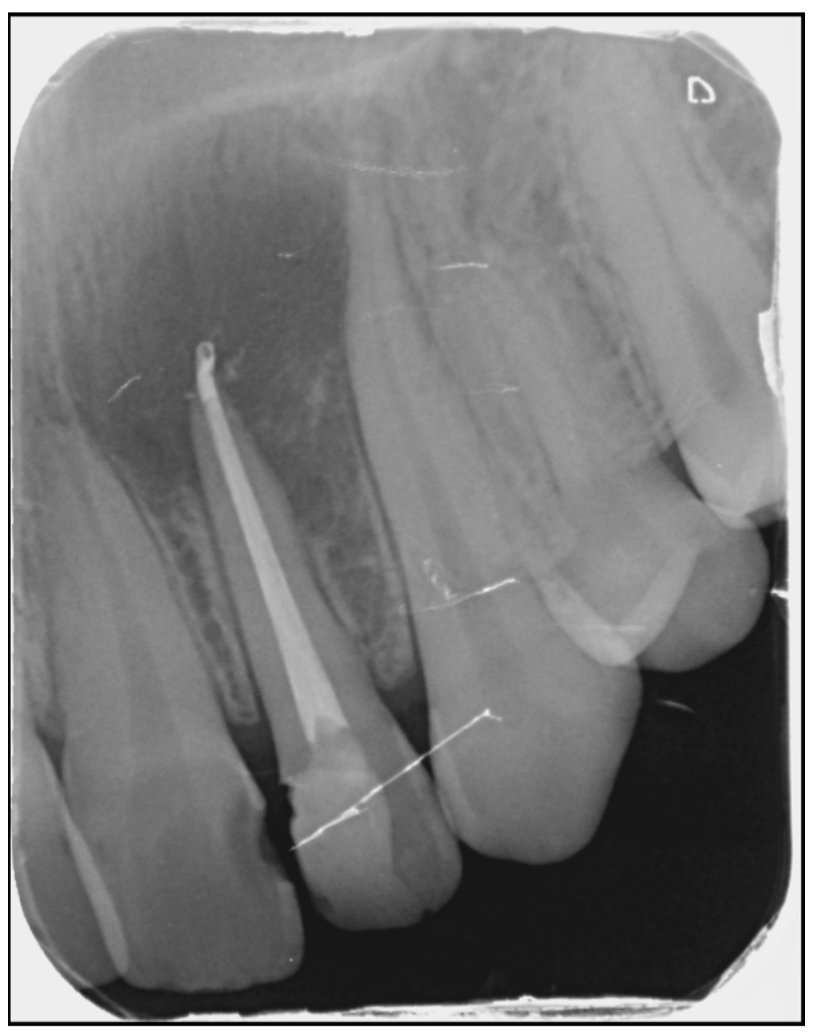

Figure 4. Postoperative rvg. 
in order to wait for the lesion to become smaller, it was decided to follow up and retreatment was not performed again. Then the follow up started. Control radiographs were taken at 1. month (Figure 5), 3. month (Figure 6), 6. month (Figure 7), 1. year (Figure 8) and then at 2. year (Figure 9) and 36. month (Figure 10).

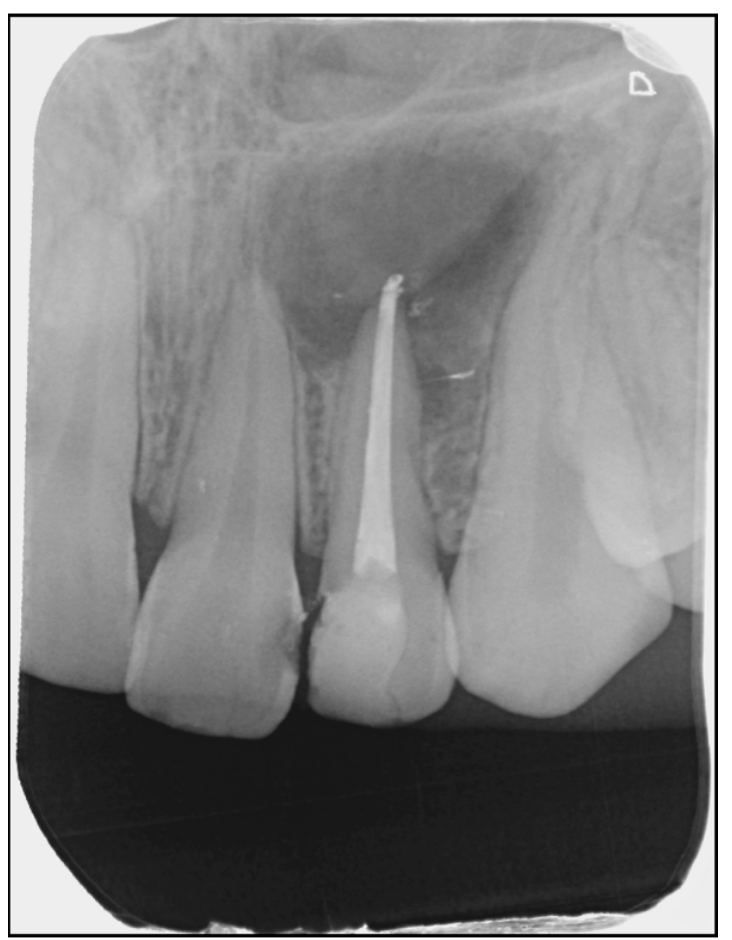

Figure 5. Postoperative rvg (1. month).

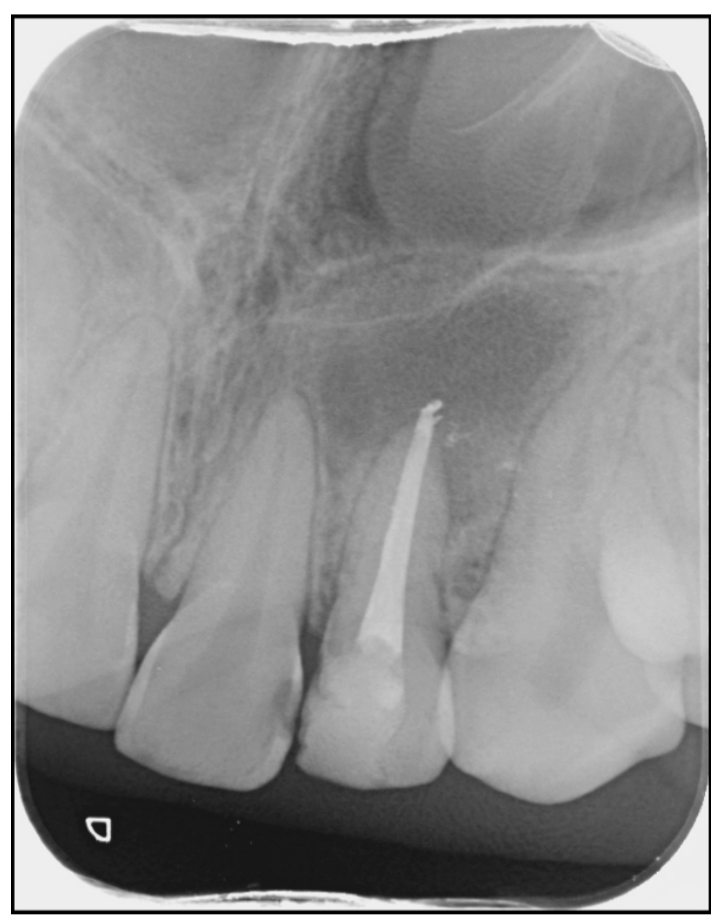

Figure 6. Postoperative rvg (3. month). 


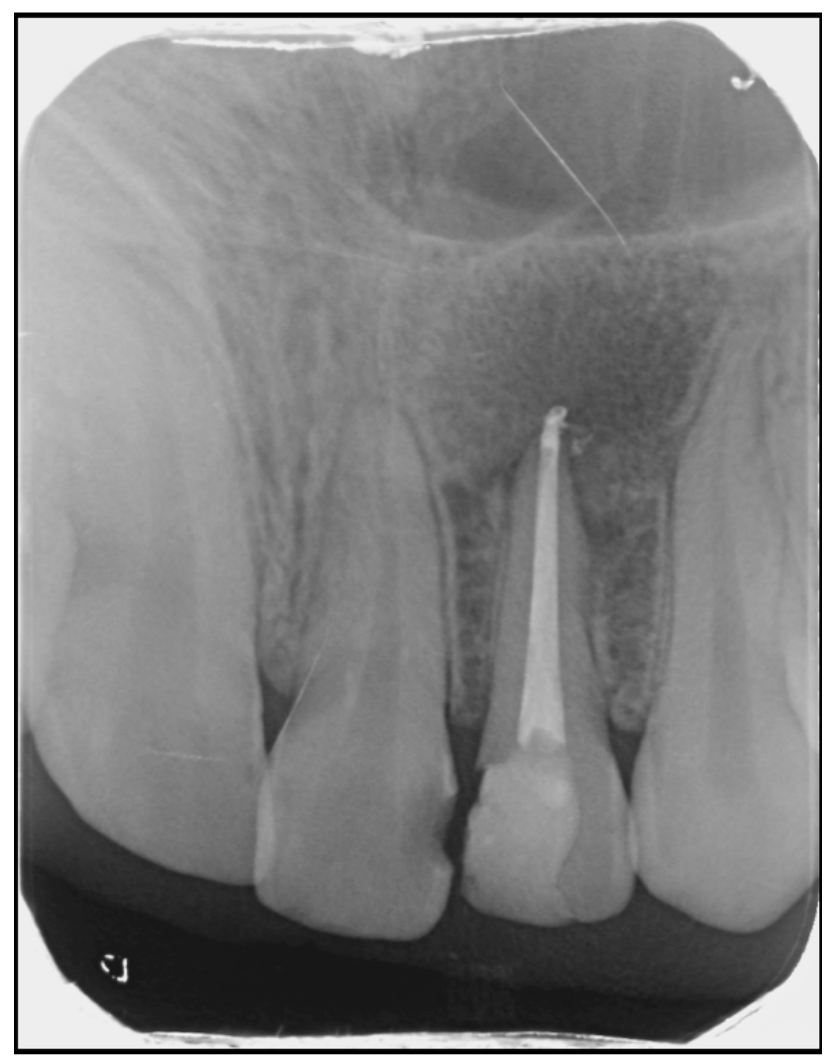

Figure 7. Postoperative rvg (6. month).

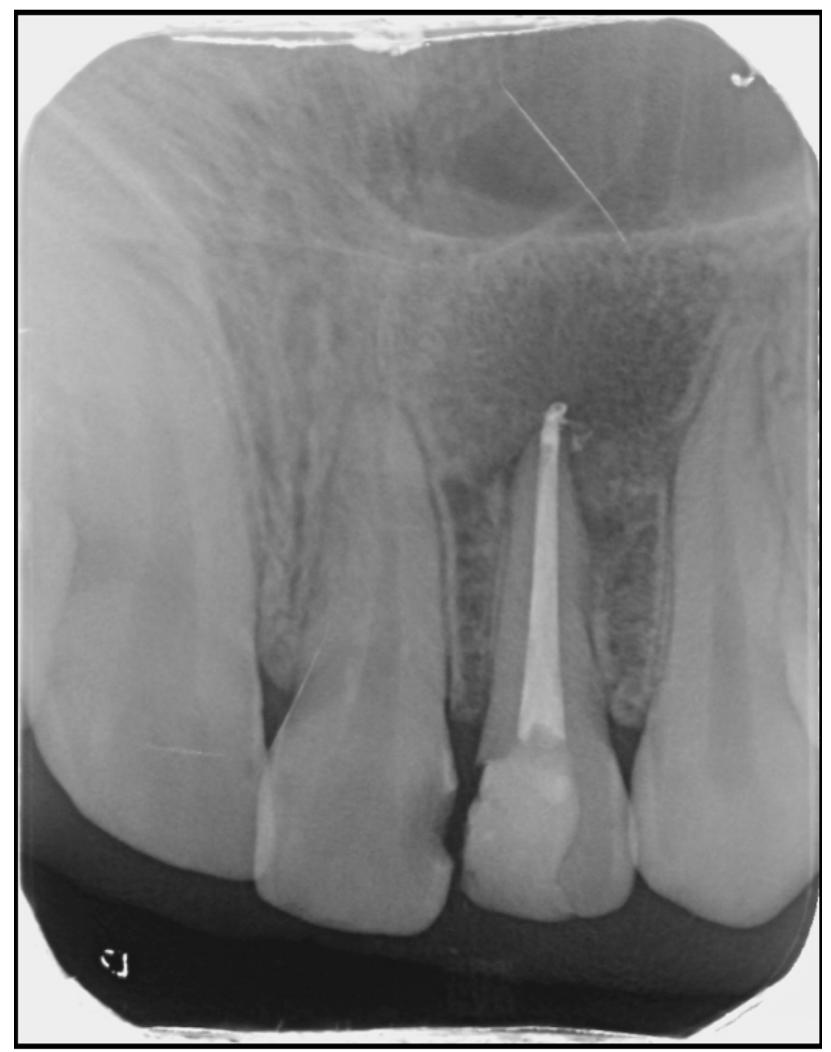

Figure 8. Postoperative rvg (1. year). 


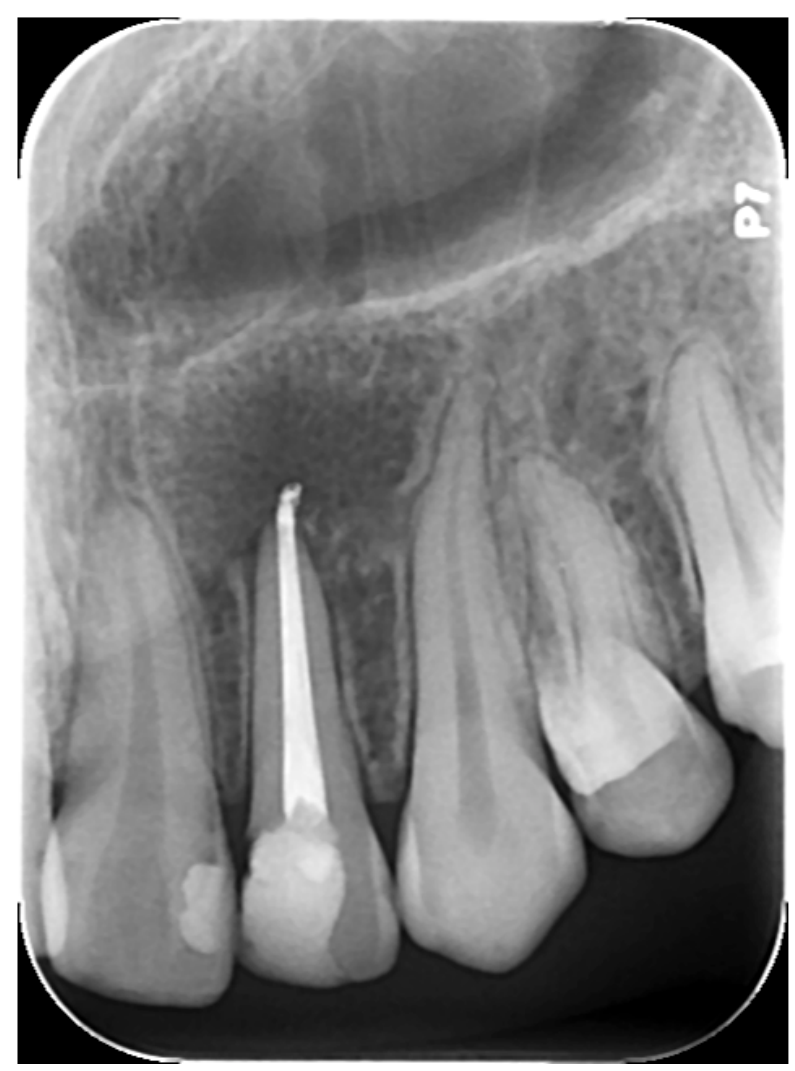

Figure 9. Postoperative rvg (2. year).

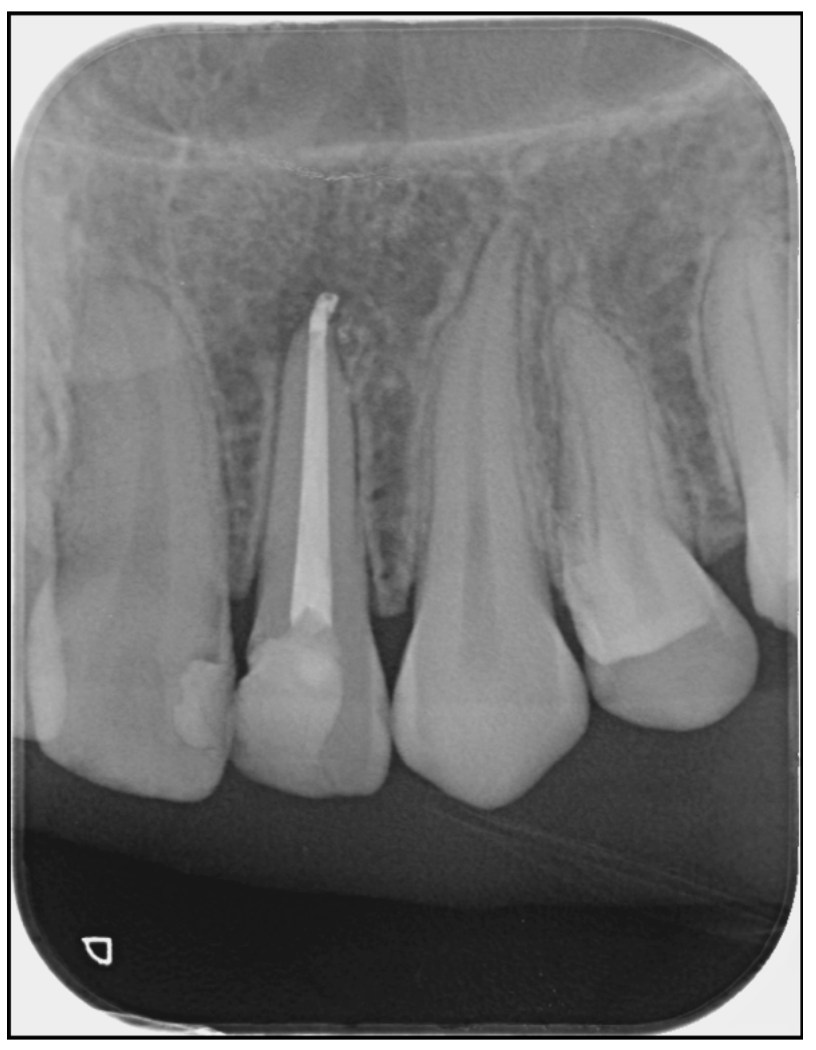

Figure 10. Postoperative rvg (36. month). 
At the first control session there was a little palpation and percussion sensitivity. But at the other control sessions the clinical findings were normal and there was no symptom. Radiographically, at the each control session we could see the healing clearly. And at the 36 months follow up session the lesion was almost completely healed and the lamina dura was visible.

\section{Discussion}

The most prevalent chronic inflammatory procedures observed in the jaws are periapical lesions; they are result of a pulp infection due to trauma or caries which causes tissue necrosis and invades the apical region [6]. Treatment of large periapical lesions ranges from nonsurgical root canal procedure and/or apical surgery to extraction. The occurence of the periradicular lesion in our case can be attributed to overinstrumentation which resulting in trauma to the periapical tissues, lack of apical seal, transportation of the intracanal bacteria and extrusion of the gutta percha during the previous root canal treatment. Although failures can appear after basic endodontic treatment, success rates after root canal therapy were reported to be quite high (84\% - 86\%) [7] [8] Basic non surgical endodontic treatment/retreatment is more simple than surgical treatment and also its acceptability by the patient is higher.

In the present study, our aim was to investigate the clinical and radiographic success rate of non-surgical endodontic therapy in maxillary anterior tooth with large periapical lesion with periodic follow-up intervals.

In this case there was about $4 \mathrm{~mm}$ extruded guta percha at the apical region and very large periapical lesion. Gutta percha is an inert material that is well tolerated by periapical tissues. [9]. In a 10-year clinical follow-up study on 775 endodontically treated teeth, Souza et al. reported a high success rate when obturation material was filled $1 \mathrm{~mm}$ below the radiographic apex [10]. When we decided to treatment there was another option like surgical treatment. A number of clinical investigations have verified that basic non-surgical endodontic treatment with adequate control of infection can provide the healing of large lesions [11] [12]. Because of patient's young age and our belief in the success of the non-surgical procedure we tried the non-surgical treatment first. One of the reasons we tried non-surgical treatment was to minimize the possibility of damage to neighboring teeth and tissues during surgery because the lesion was too large and too close to the adjacent teeth. The adjacent teeth were vital so we tried our best option to maintain the vitality of the teeth.

In a case report published in 2013, a 16-year-old patient had retreatment in the upper central tooth; Similar to our case, non-surgical treatment of extruded material has been shown [13]. In a case report published in February 2021, it was shown that the lesion at the apical region healed after 2-year follow-up with non-surgical retreatment of a tooth with extruded material [14]. As in our case, it has been observed that even large lesions can heal in the retreatments of the overflowed root canal filling with adequate chemomechanical cleaning, infection 
control and correct obturation in these cases.

The main purpose of endodontic treatment is to prevent and eliminate the formation of apical lesions by cleaning, shaping, disinfecting and obturation the root canal system and keeping the tooth in function. Mechanical cleaning alone does not completely remove microorganisms or their products from root canals. Peters et al [15] showed that more than 35\% of the root canal walls remained untouched even with the use of a recent nickel-titanium rotary tool. Therefore; elimination of microorganisms and biofilms is achieved by mechanical cleaning, irrigation with tissue dissolving and antimicrobial agents, and application of antimicrobial drugs to the root canal between sessions. So, we used $2.5 \% \mathrm{NaOCl}$ and $17 \%$ EDTA combinations, because of being the most commonly used and the most effective irrigation solutions in endodontic treatment [16].

Drainage is one of the necessary treatment approaches for effective treatment in teeth with large periapical lesions. There are histological studies advocating the necessity of drainage [17]. When direct and immediate drainage from localized swelling or abscesses or cysts is achieved, symptoms are reduced. In our case there was no swelling but when we remove the extruded gutta percha the drainage took place for four session. An assessment of radiographic results and the existence or absence of clinical signs and symptoms of the treated tooth at the time of control sessions are the basis for the achievement of endodontic treatment. Some studies describe achievement based on radiographic healing [18] while others consider the treatment successful if the tooth stays in the oral cavity and functions [19].

The healing process depends on the structural and functional replacement of the affected areas by intrinsic or extrinsic factors. Studies evaluating the success of endodontically treated teeth showed that overfills delayed the apical repair process [20] [21] [22]; in our case, the patient was asymptomatic during the follow-up period, the tooth was in function, and the lesion healed a little more in each control radiography.

After root canal treatment, clinical and radiographic improvement should be evaluated by performing a control examination periodically. Situations such as absence of pain, swelling and other symptoms, no loss of function, absence of sinus tract and radiological evidence of a normal periodontal ligament space around the tooth indicate recovery. In our cases there is follow up for 36 months. The first year of follow-up was completed: the first follow-up appointment was at the end of the first month, the second one was at the end of the 3rd month, then the third control was at the 6th month and the fourth control was at the $12^{\text {th }}$ month. Then, a control appointment was performed again at 24 and 36 months. Despite about $4 \mathrm{~mm}$ of gutta-percha that were pushed into the periradiculer tissues and the finally $1 \mathrm{~mm}$ overfill, there was healing of the periradiculer tissues 36 months after the completion of the root canal treatment and the patient remained asymptomatic. The case was considered successful according to the criteria for evaluating the success of endodontic treatment [23]. 
Systematic reviews have shown that root canal preparation and obturation inferior to the radiographic apex (root canal obturation at $1-2 \mathrm{~mm}$ inferior to the apex) were associated with a better prognosis (higher success rates) [24].

In this case the healing of the lesion was attributed to the successful control of infection during the root canal treatment process such as root canal preparation, debridement and obturation. This healing process was not affected by the presence of filling material in the periapical tissues and it is also an agreement with studies that report guta percha to be well-tolerated [25]. If the desired result could not be achieved after retreatment, the patient was informed about apical resection. Fortunately, after 36 months of follow-up, the patient was asymptomatic and almost completely healed radiographically. In addition, in this case regeneration of bone trabeculation and lamina dura remodeling were observed after 36 months of follow-up.

\section{Conclusion}

Gutta-percha extrusion from the apical region is one of the complications that can be encountered during root canal treatment. Failure to use proper material during root canal treatment may be the reason for this complication. If this complication is not resolved, extruded gutta percha may cause foreign body reaction in the long term and result in lesion formation in the periapical area. In such a case, nonsurgical retreatment should be the preferred choice as it is a more conventional treatment and does not require a second surgical procedure. if the desired result cannot be achieved with non-surgical retreatment; surgical treatment can be offered to the patient as an alternative treatment option, considering its advantages and disadvantages.

\section{Conflicts of Interest}

The author declares no conflicts of interest regarding the publication of this paper.

\section{References}

[1] Schilder, H. (1967) Filling Root Canal in Three-Dimensions. Dental Clinics of North America, 32, 723-744.

[2] Johnson, B.R., Fayad, M.I. and Witherspoon, D.E. (2011) Periradicular Surgery. In: Hargreaves, K.M., Cohen, S. and Berman, L.H., Eds., Cohen's Pathways of the Pulp, 10th Edition, Elsevier Inc., Missouri, 720-776. https://doi.org/10.1016/B978-0-323-06489-7.00021-7

[3] Nair, P.N. (1998) New Perspectives on Radicular Cysts: Do They Heal? International Endodontic Journal, 31, 155-160. https://doi.org/10.1046/j.1365-2591.1998.00146.x

[4] Kim, S. and Kratchman, S. (2006) Modern Endodontic Surgery Concepts and Practice: A Review. Journal of Endodontics, 32, 601-623.

[5] Layton, C.A., Marshall, J.G., Morgan, L.A. and Baumgartner, J.C. (1996) Evaluation of Cracks Associated with Ultrasonic Root-End Preparation. Journal of Endodontics, 22, 157-160. 
[6] Mirković, S., Tadić, A., Đurđević-Mirković, T. and Aleksandra, L. (2012) Comparative Analysis of Accuracy of Diagnosis of Chronic Periapical Lesions Made by Clinical and Histopatological Examination. Medicinski Pregled, 65, 277-280. https://doi.org/10.2298/MPNS1208277M

[7] Torabinejad, M., Anderson, P., Bader, J., Jackson Brown, L., Chen, L.H., et al. (2007) Outcomes of Root Canal Treatment and Restoration, Implant Supported Single Crowns, Fixed Partial Dentures, and Extraction without Replacement: A Systematic Review. Journal of Prosthetic Dentistry, 98, 285-311. https://doi.org/10.1016/S0022-3913(07)60102-4

[8] Salehrabi, R. and Rotstein, I. (2004) Endodontic Treatment Outcomes in a Large Patient Population in the USA: An Epidemiological Study. Journal of Endodontics, 30, 846-850.

[9] Swartz, D.B., Skidmore, A.E. and Griffin Jr., J.A. (1983) Twenty Years of Endodontic Success and Failure. Journal of Endodontics, 9, 198-202.

[10] Imura, N., Pinheiro, E.T., Gomes, B.P., Zaia, A.A., Ferraz, C.C. and Souza-Filho, F.J. (2007) The Outcome of Endodontic Treatment: A Retrospective Study of 2000 Cases Performed by a Specialist. Journal of Endodontics, 33, 1278-1282.

[11] Oztan, M.D. (2002) Endodontic Treatment of Teeth Associated with a Large Periapical Lesion. International Endodontic Journal, 35, 73-78. https://doi.org/10.1046/j.1365-2591.2002.00455.x

[12] Çalışkan, M.K. (2004) Prognosis of Large Cyst-Like Periapical Lesions Following Nonsurgical Root Canal Treatment: A Clinical Review. International Endodontic Journal, 37, 408-416. https://doi.org/10.1111/j.1365-2591.2004.00809.x

[13] Vivekananda, P.A.R. and Thapa, A. (2013) Non-Surgical Retrieval of Gutta Percha Including an Extruded One Using a Barbed Broach-A Case Report. Journal of Nepal Dental Association, 13, 78-81

[14] Almutairi, N. (2021) A Nonsurgical Approach for Removal of Overfilling Guttapercha: Case Report. International Journal of Dental Sciences and Research, 9, 20-22. https://doi.org/10.12691/ijdsr-9-1-5

[15] Peters, O.A., Schonenberger, K. and Laib, A. (2001) Effects of four Ni-Ti Preparation Techniques on Root Canal Geometry Assessed by Micro Computed Tomography. International Endodontic Journal, 34, 221-230. https://doi.org/10.1046/j.1365-2591.2001.00373.x

[16] Dutner, J., Mines, P. and Anderson, A. (2012) Irrigation Trends among American Association of Endodontists Members: A Web-Based Survey. Journal of Endodontics, 38, 37-40.

[17] Fujii, H. and Machida, Y. (1991) Histological Study of Therapy for Infected Nonvital Permanent Teeth with Incompletely Formed Apices. Bulletin of Tokyo Dental College, 32, 35-45.

[18] Strindberg, L. (1956) The Dependence of the Results of Pulp Therapy on Certain Factors-An Analytical Study Based on Radiographic and Clinical Follow-up Examination. Acta Odontologica Scandinavica, 14, 1-175.

[19] Friedman, S., Abitbol, S. and Lawrence, H.P. (2003) Treatment Outcome in Endodontics: The Toronto Study. Phase 1: Initial Treatment. Journal of Endodontics, 29, 787-793.

[20] Holland, R., Mazuqueli, L., Souza, V., Murata, S.S., Dezan Jr., E. and Suzuki, P. (2007) Influence of the Type of Vehicle and Limit of Obturation on Apical and Periapical Tissue Response in Dogs' Teeth after Root Canal Filling with Mineral Trioxide Aggregate. Journal of Endodontics, 33, 693-697. 
[21] Suzuki, P., Souza, Vd., Holland, R., Gomes-Filho, J.E., Murata, S.S., Dezan Jr., E., et al. (2011) Tissue Reaction to Endométhasone Sealer in Root Canal Fillings Short of or Beyond the Apical Foramen. Journal of Applied Oral Science, 19, 511-516. https://doi.org/10.1590/S1678-77572011000500013

[22] Suzuki, P., Souza, V., Holland, R., Murata, S.S., Gomes-Filho, J.E., Dezan Jr., E., et al. (2010) Tissue Reaction of the EndoREZ in Root Canal Fillings Short of or Beyond an Apical Foramenlike Communication. Oral Surgery, Oral Medicine and Oral Pathology, 109, e94-e99. https://doi.org/10.1016/j.tripleo.2009.12.047

[23] Bender, I., Seltzer, S. and Soltanoff, W. (1966) Endodontic Success a Reappraisal of Criteria. Oral Surgery, Oral Medicine and Oral Pathology, 22, 790-802. https://doi.org/10.1016/0030-4220(66)90369-0

[24] Schaeffer, M.A., White, R.R. and Walton, R.E. (2005) Determining the Optimal Obturation Length: A Meta-Analysis of Literature. Journal of Endodontics, 31, 271274.

[25] Wolfson, E. and Seltzer, S (1975) Reaction of Rat Connective Tissue to Some Gutta-Percha Formulations. Journal of Endodontics, 1, 395402.

https://doi.org/10.1016/S0099-2399(75)80158-0 